\title{
Hull Girder Ultimate Strength Assessment Considering Local Corrosion
}

\author{
Van Tuyen $\mathrm{Vu}^{1} \cdot$ Duc Tuan Dong ${ }^{1}$
}

Received: 22 December 2019 / Accepted: 27 July 2020 / Published online: 9 October 2020

(C) The Author(s) 2020, corrected publication 2021

\begin{abstract}
The residual strength capacity of ship hull with full corrosion appearance in every structural member has been considered in a large number of research works; however, the influence of local corrosion on the ultimate strength and cross-section properties has not been taken into account and analyzed. Hence, this study aims to assess the effect of corrosion appearance in the flange section and web section on the ultimate vertical bending moment and several cross-section properties of a bulk carrier. To perform this task, a probabilistic corrosion rate estimation model and the common structural rule model are introduced and employed. The incremental-iterative method given by the International Association of Classification Societies-Common Structural Rules (IACS-CSR) is applied to determine the ultimate vertical bending moment, neutral axis position at the limit state, and other properties of the cross-section. The calculation results and discussions relative to the effect of corrosion on ship hull are presented.
\end{abstract}

Keywords Corrosion wastage $\cdot$ Corrosion model $\cdot$ Ultimate strength $\cdot$ Ship hull $\cdot$ Cross-section

\section{Introduction}

The aging ship structures always comprise several damages such as corrosion, fatigue cracks, and local dents. Among these factors, corrosion is the most important and serious (Kim et al. 2012a). The corrosion wastage might appear in every zone of ship structures, but several locations in the hold are more susceptible to corrosion than others such as the inner bottom, lower and upper sloping plates, hold frame, side shell plate, deck plate, shear strake, and deck longitudinal (Paik et al. 1998). The corrosion appearance in the marine structures is

\section{Article Highlights}

- The total cross-sectional area (CSA) of all longitudinal stiffeners in a panel is always smaller than this value of the attached plating in the same panel.

- For bulk carriers, the CSA of side panel is the biggest, but the influence of the CSA reduction on ultimate bending moment (UBM) degradation is the smallest.

- Deck panel has the most effect on the UBM of bulk carriers.

Van Tuyen Vu

tuyenvv.dt@vimaru.edu.vn

1 Faculty of Shipbuilding, Vietnam Maritime University, Haiphong 180000, Vietnam caused by a large number of factors such as protection systems, type of cargo, temperature, humidity, oxygen content, $\mathrm{pH}$ level, and chemical composition (Paik et al. 2003c). Due to the complex working environment of marine structures, many modes of corrosion can appear in the metal's surface such as general corrosion, pitting corrosion, grooving corrosion, crevice corrosion, galvanic corrosion, erosion-corrosion, cavitation, stress corrosion, and corrosion fatigue (Guedes Soares and Garbatov 1997).

Facts indicate that the pitting corrosion and general corrosion are the most popular in the marine structures. To the pitting corrosion, several parameters such as pit depth, pit diameter, shape of pit, location of pit, and degree of pit (DOP) are employed to assess the effect of pitting corrosion on the structure behaviors (Paik et al. 2003b; Guedes Soares et al. 2009). Meanwhile, the annual corrosion rate is often applied to evaluate the effect of general corrosion on the structure responses. Concerning this, the existing research works investigated and published the annual corrosion rate for different types of ships. Specifically, Paik et al. (1998) surveyed 7503 corrosion data of 44 existing bulk carriers and suggested the annual corrosion rate for 34 different location groups of bulk carriers. Paik et al. 


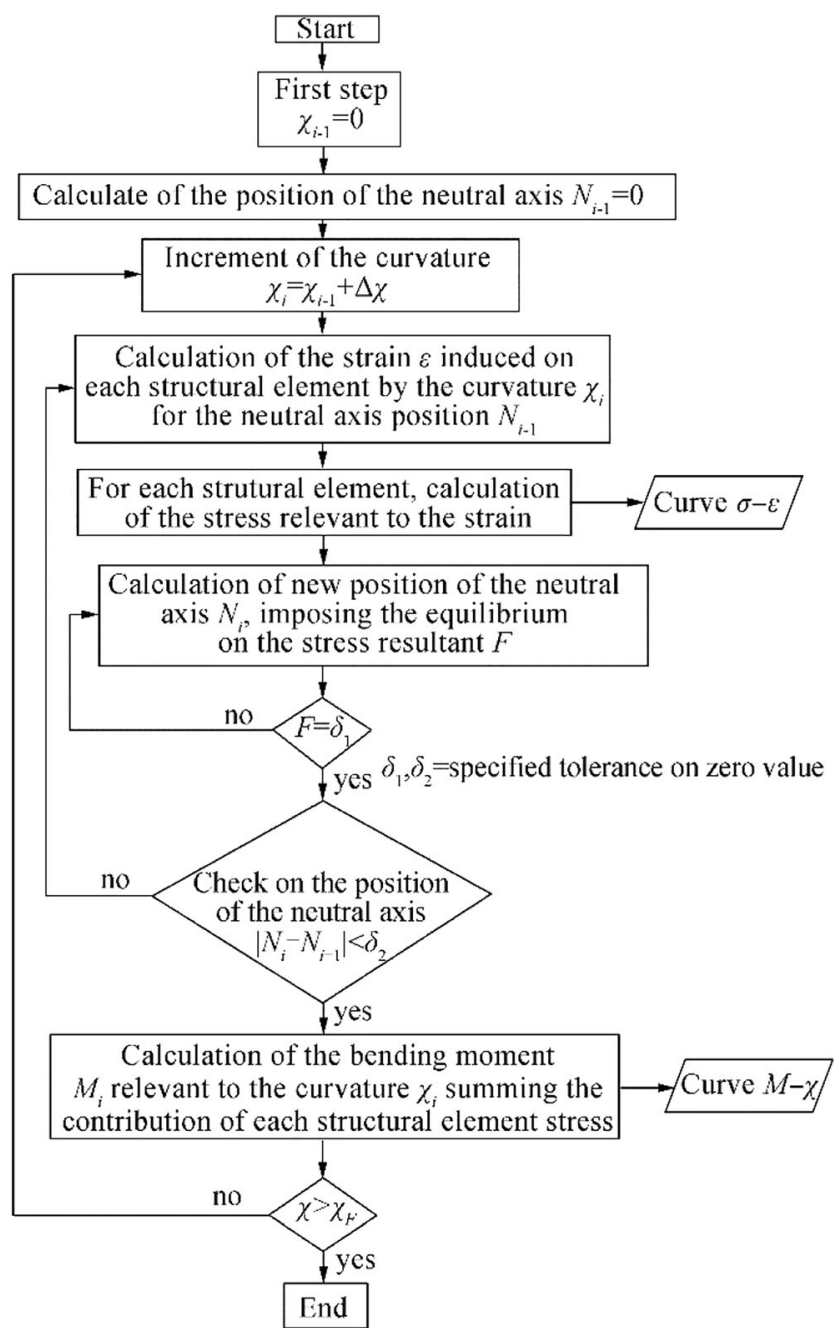

Figure 1 Flow chart of the procedure for the evaluation of the $M-\chi$ curve

(2003a, d) measured corrosion data for 230 aging single-hull tankers with 33820 measurements for 34 different member categories including 14 groups of plate parts, 11 groups of stiffener webs, and 9 groups of stiffener flanges. This study also gave the corrosion rate for 34 different member groups of double-hull tankers or floating production storage and offloading (FPSOs). The annual corrosion rate of oil tankers and FPSOs was also presented in research works of Guedes Soares and Garbatov (1999), Akpan et al. (2002), and

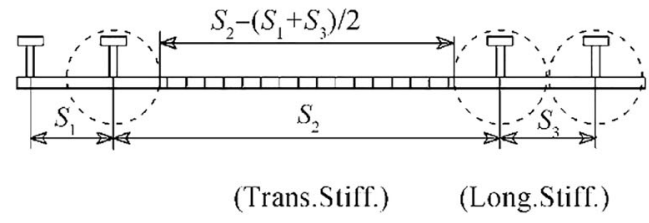

Stiffened plate element $\quad \because$; Stiffener element Hard corner element

Kim et al. (2014b). Guedes Soares and his partners did an investigation of the effect of environmental factors on corrosion of ship structures in the marine atmosphere. A new corrosion model was proposed in predicting corrosion degradation in short-term and long-term ship lifetime (Guedes Soares et al. 2009). The real parameters of corrosion are used to evaluate the existing corrosion wastage models (Garbatov et al. 2007; Garbatov and Guedes Soares 2008). The corrosion addition was suggested to apply to container ships as the common corrosion addition rule to determine the ultimate longitudinal strength (Kim et al. 2012a). According to the IACS-CSR guidelines, the corrosion addition is applied to both bulk carriers and oil tankers for the design problem or strength assessment (IACS 2017). Zayed et al. (2018) developed a new corrosion model to predict corrosion degradation of ship plates on both sides in different ship spaces. This model was built based on the assessment of the local environmental conditions including chemical and physical characteristics. A Suezmax oil tanker, an Aframax oil tanker, and double-hull tankers are selected in studies of Guedes Soares and Parunov (2008), Parunov and Guedes Soares (2008), and Gaspar et al. (2011), respectively. These studies mentioned the new common structural rules given by IACS which affect the hull girder ultimate strength of tankers.

The effect of corrosion wastage on the ultimate strength of hull structural plates was covered in several studies. To be more specific, several parameters of pitting corrosion including the location of pit, pit depth, and one-sided or two-sided corrosion were employed to assess the ultimate strength of plate under uniaxial compression (Ok et al. 2007; Jiang and Guedes Soares 2013). The biaxial load and other factors such as volume loss, plate slenderness, aspect ratio, distribution, and pit depth were applied to evaluate the residual strength of the hull structural plate (Huang et al. 2010). Meanwhile, Paik (2005) assessed the ultimate strength of the dented steel plate under the edge shear loads. This study considered the parameters namely pit shape, pith depth, pit diameter, location of pit, different plate thickness, and aspect ratio, and the nonlinear finite

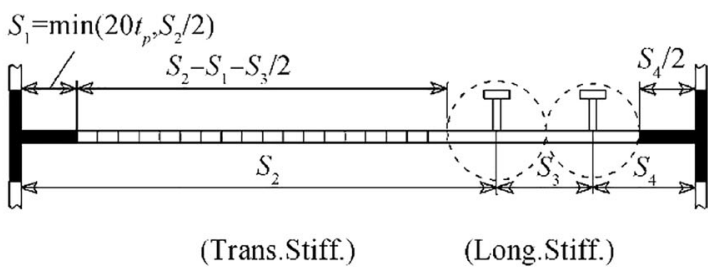


Table 1 Modes of failure of individual structural elements

\begin{tabular}{|c|c|c|}
\hline Element & Mode of failure & Curve $\sigma-\varepsilon$ defined as \\
\hline $\begin{array}{l}\text { Lengthened stiffened plate element } \\
\text { or stiffener element }\end{array}$ & Elasto-plastic collapse & $\sigma=\Phi R_{\mathrm{eHA}}$ \\
\hline \multirow[t]{4}{*}{ Shortened stiffener element } & Beam column buckling & $\sigma_{\mathrm{CR} 1}=\Phi \sigma_{C 1} \frac{A_{s-n 50}+A_{p E-n 50}}{A_{s-n 50}+A_{p-n 50}}$ \\
\hline & Torsional buckling & $\sigma_{\mathrm{CR} 2}=\Phi \frac{A_{s-n 50} \sigma_{C 2}+A_{p-n 50} \sigma_{\mathrm{CP}}}{A_{s-n 50}+A_{p-n 50}}$ \\
\hline & Web local buckling of flanged profiles & $\sigma_{\mathrm{CR} 3}=\Phi \frac{10^{3} b_{E} t_{n 50} R_{\mathrm{eHp}}+\left(h_{w e} t_{w-n 50}+b_{f} t_{f-n 50}\right) R_{\mathrm{eHs}}}{10^{3} s t_{n 50}+h_{w} t_{w-n 50}+b_{f} t_{f-n 50}}$ \\
\hline & Web local buckling of flat bars & $\sigma_{\mathrm{CR} 4}=\Phi \frac{A_{s-n 50} \sigma_{C 4}+A_{p-n 50} \sigma_{\mathrm{CP}}}{A_{s-n 50}+A_{p-n 50}}$ \\
\hline Shortened stiffened pate element & Plate buckling & $\sigma_{\mathrm{CR} 5}=\min \left\{\Phi R\left[s(2.25-1.25)+0(1-s)(1+1)^{2}\right]\right.$ \\
\hline Hard corner element & Elasto-plastic collapse & 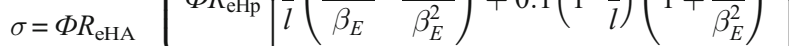 \\
\hline
\end{tabular}

Figure 3 Corrosion addition margins of a bulk carrier structure specified by the CSR

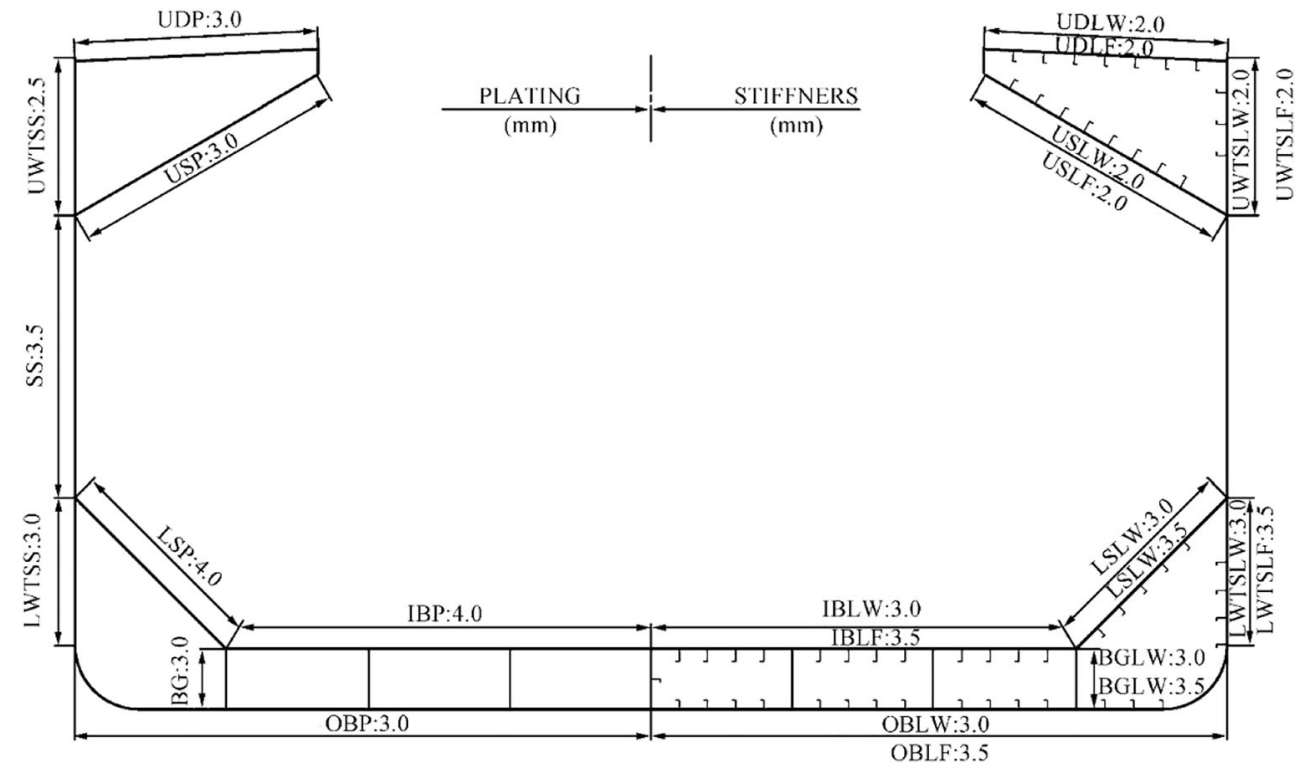

element method was used to analyze the dented plates. Another type of load is the tensile force which was employed to analyze the strength capacity of corroded wide steel plates. The effective thickness, initial thickness, and standard deviation were also applied (Kaita et al. 2011). According to the study by Zhang et al. (2016), the combination of loadings was applied. With regard to this, biaxial load combined with shear load was employed, and other factors related to corrosion wastage were also used to assess the variations of the ultimate strength of hull structural plates.

Regarding the stiffened plates, Dunbar et al. (2004) conducted an assessment of the initial buckling, ultimate collapse, and post-ultimate responses of a corroded stiffened panel. This study used local corrosion and initial imperfections (initial distortions and residual stresses) to assess the strength of a stiffened panel. Wang et al. (2015) applied grooving corrosion

Figure 4 Probabilistic corrosion rate estimation model 
Figure 5 Corrosion rate of member location groups of bulk carrier

Table 2 Identification of member location groups of bulk carrier

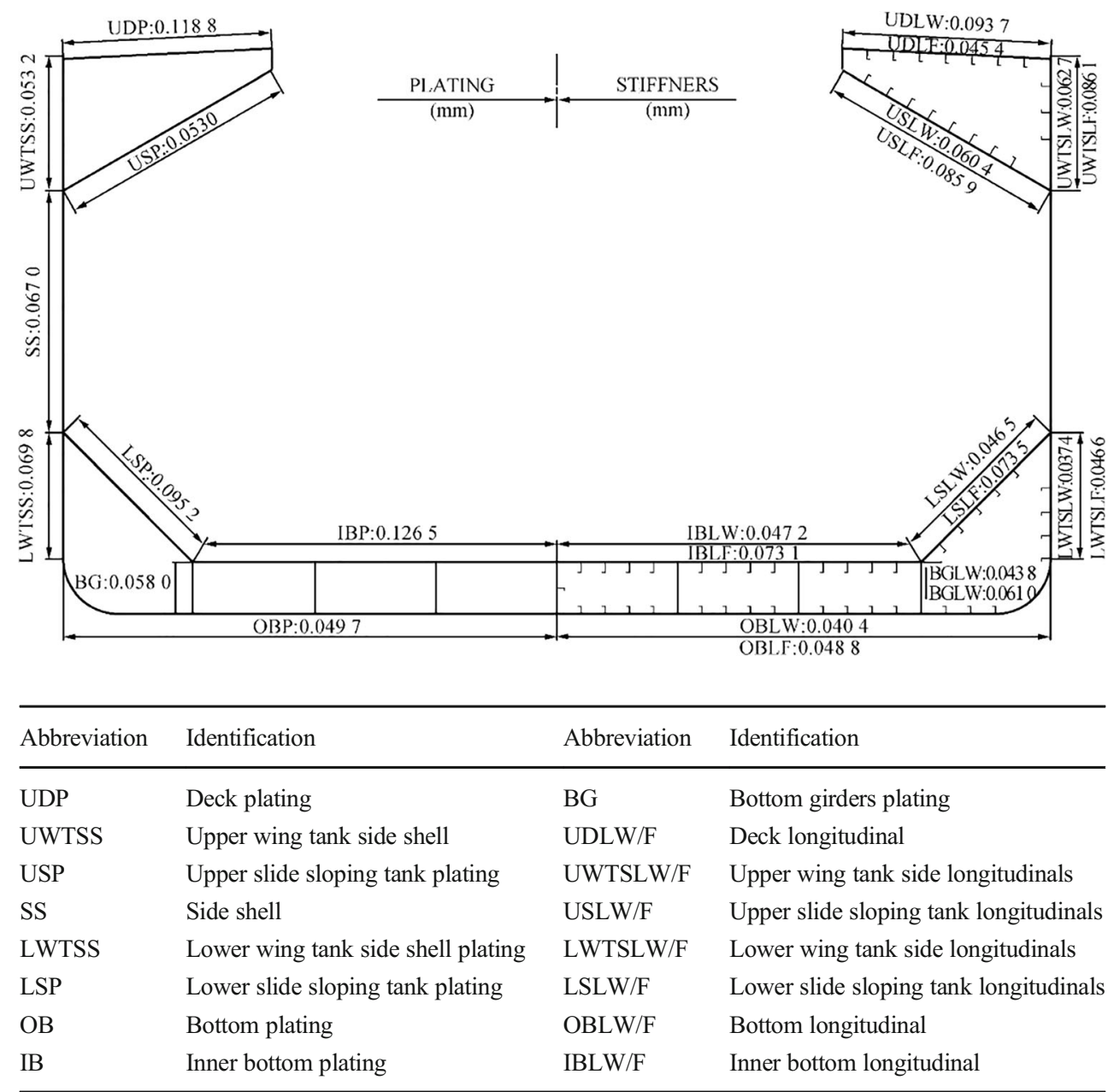

Notes: The ending letter "P" is denoted for plating, "W" is denoted for the web, and " $\mathrm{F}$ " is denoted for the flange and other factors such as initial imperfections (initial deflections and residual stresses) and corrosion parameters (grooving depth and volume loss) to assess the ultimate strength of a stiffened panel. The grooving corrosion is assumed to appear in the attached plating and the bottom of the stiffener web. The corroded stiffened plates with irregular surfaces with different corrosion patterns, amount of corrosion loss, and roughness of surface were employed to assess the elastic buckling strength (Rahbar-Ranji 2015) while pitting corrosion was used to evaluate the ultimate strength of stiffened plate (Jing et al. 2017; Rahbar-Ranji et al. 2015).

The corrosion wastage was employed to assess the ship hull girder responses by several authors groups. Paik et al. (2001) developed a closed-form ultimate strength formulation to determine the UBM and neutral axis position at the limit state. This formulation was applied to evaluate the effect of some factors such as initial imperfections (initial distortions and residual stresses) and potential structural damages (corrosion, collision, and grounding) on the ultimate vertical bending moment of a bulk carrier. Meanwhile, Paik et al. (2003d) applied two annual corrosion rate models namely average and severe corrosion rate to analyze the influence of them on the ultimate longitudinal bending moment and section modulus of a bulk carrier. The ultimate longitudinal strength and section modulus of a single-hull VLCC under the thickness degradation due to corrosion wastage were also analyzed. The $15 \%$ diminution of section modulus and the linear relationship of the ultimate longitudinal strength were found (Ikeda et al. 2001). The residual strength of a container ship with corrosion and fatigue cracks was investigated. The

Table 3 Principal dimensions of selected bulk carrier

\begin{tabular}{lllllll}
\hline Principles & $\begin{array}{l}\text { Deadweight } \\
\text { (ton) }\end{array}$ & $\begin{array}{l}\text { LBP } \\
(\mathrm{m})\end{array}$ & $\begin{array}{l}\text { Beam width } \\
(\mathrm{m})\end{array}$ & $\begin{array}{l}\text { Depth } \\
(\mathrm{m})\end{array}$ & $\begin{array}{l}\text { Double bottom } \\
\text { height }(\mathrm{m})\end{array}$ & $\begin{array}{l}\text { Block } \\
\text { coefficient }\end{array}$ \\
\hline Value & 56000 & 185.0 & 32.26 & 18.1 & 1.68 & 0.826 \\
\hline
\end{tabular}


Figure 6 Member location groups of the bottom, side, and deck panel of bulk carrier

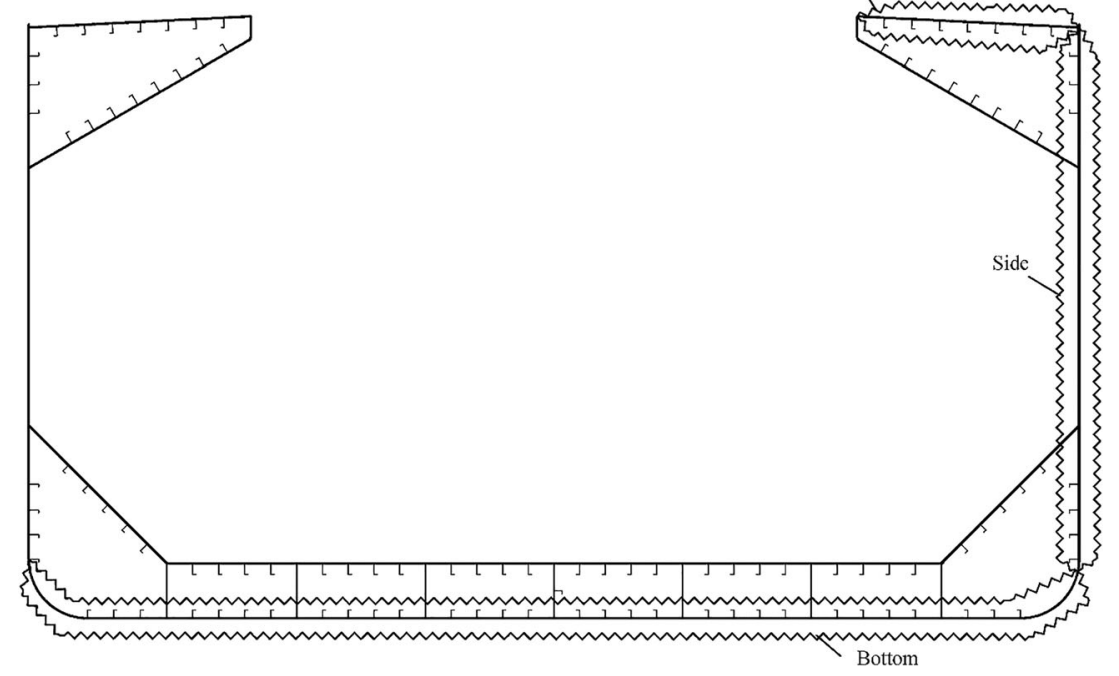

results showed that uniform corrosion has the biggest reduction in hogging ultimate strength, while the sagging ultimate strength has the smallest diminution (Gao et al. 2012). Kim et al. performed a series of assessments of the effect of corrosion wastage on the ultimate strength responses of four types of oil tankers namely VLCC, Suezmax, Aframax, and Panamax (Kim et al. 2012b, 2014a, b; Guedes Soares and Garbatov 1999). The average general corrosion thickness degradation model and real corrosion model are expropriated to assess the influence of corrosion on the ultimate bending moment of two box girders (Saad-Eldeen et al. 2013). The ultimate strength reduction and cross-section properties of a double-hull VLCC were assessed. Two corrosion rate models with three assumptions of coating lifetime were employed. The study showed that all the reductions follow a linear relationship except a neutral axis position (Vu Van and Yang 2017). Zayed et al. (2013) conducted an assessment of lifetime reliability of the ship hull structures consideration corrosion degradation, inspection activity, and ship loading. The ultimate vertical bending moment capacity of the ship hull is employed in a reliability problem

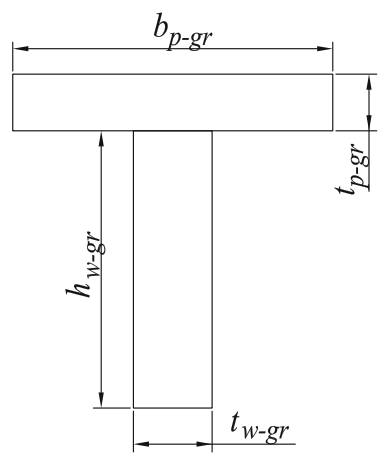

(a) Flat bar

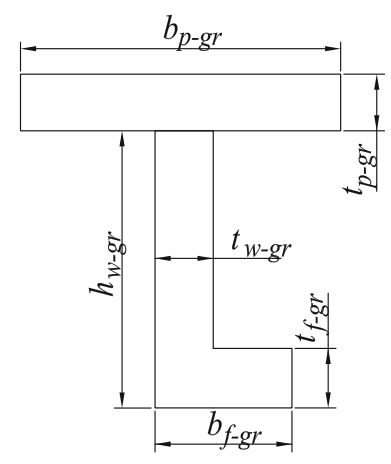

(b) L profile
Figure 7 Nomenclature of the plate-stiffener combination element dimensions. a Flat bar. b L profile and an algorithm was developed to assess the structural reliability of ship hull.

The above-mentioned research works have limitations in assessing the effect of corrosion wastage on the ultimate strength of the unstiffened plates, stiffened plates, or hull girders. In terms of ship hull girder, the corrosion wastage is assumed that entire cross-section structures are corrosive with different corrosion levels. Therefore, this study aims to assess the UBM and cross-section properties under the effect of corrosion appearance in stiffeners, attached plating, or whole panel. The incrementaliterative method combined with two corrosion models is applied. The results and discussions are also presented.

\section{Applied Methods and Parameters}

\subsection{Incremental-Iterative Method}

The IACS-CSR developed the incremental-iterative method for determining the bending moment of ship hull girder which considers the critical failure modes of all main

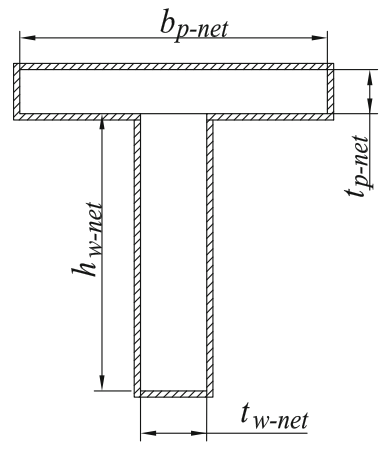

(a) Flat bar

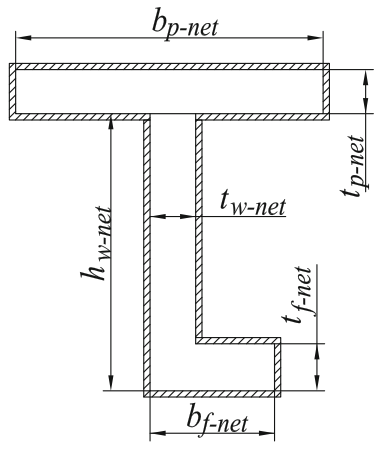

(b) L profile
Figure 8 Schematic of a corroded plate-stiffener combination element. a Flat bar. b L profile 
Table 4 Thickness degradation due to corrosion wastage

\begin{tabular}{|c|c|c|c|c|}
\hline Location & Scantlings & $t_{\mathrm{p}}(\mathrm{mm})$ & $t_{\mathrm{w}}(\mathrm{mm})$ & $t_{\mathrm{f}}(\mathrm{mm})$ \\
\hline \multirow[t]{6}{*}{ Deck } & $0-7.5$ years & 26.000 & 12.000 & 17.000 \\
\hline & 10 years & 25.703 & 11.766 & 16.887 \\
\hline & 15 years & 25.109 & 11.297 & 16.660 \\
\hline & 20 years & 24.515 & 10.829 & 16.433 \\
\hline & 25 years & 23.921 & 10.360 & 16.206 \\
\hline & CSR net & 22.000 & 8.000 & 12.500 \\
\hline \multirow[t]{6}{*}{ Side } & $0-7.5$ years & 16.500 & 12.000 & 17.000 \\
\hline & 10 years & 16.326 & 11.907 & 16.884 \\
\hline & 15 years & 15.977 & 11.720 & 16.651 \\
\hline & 20 years & 15.628 & 11.533 & 16.418 \\
\hline & 25 years & 15.279 & 11.346 & 16.185 \\
\hline & CSR net & 13.500 & 9.000 & 13.500 \\
\hline \multirow[t]{6}{*}{ Bottom } & $0-7.5$ years & 19.000 & 12.000 & 16.000 \\
\hline & 10 years & 18.876 & 11.899 & 15.878 \\
\hline & 15 years & 18.627 & 11.697 & 15.634 \\
\hline & 20 years & 18.379 & 11.495 & 15.390 \\
\hline & 25 years & 18.130 & 11.293 & 15.146 \\
\hline & CSR net & 16.000 & 9.000 & 12.500 \\
\hline
\end{tabular}

longitudinal structural elements belonging to each transverse section and has some assumptions as follows (IACS 2017):

- The ultimate strength is calculated based on the hull transverse sections between the two adjacent transverse webs.

- The hull girder transverse section remains plane during each curvature increment.
- The hull material displays an elasto-plastic behavior.

The hull girder transverse section is categorized into a set of elements, which act independently from one another. In determining the UBM, the following main steps are followed concurrently as in the flow chart shown in Figure 1, which results in the $M-\chi$ curve.

- Step 1: Divide the transverse section of the hull into several stiffened plate elements.

- Step 2: Define the stress-strain relationships among all elements.

- Step 3: Initialize neutral axis and curvature $\chi_{1}$ for the first incremental step.

- Step 4: Calculate the corresponding stress $\sigma_{i}$ and corresponding strain $\varepsilon_{i}$ for each element.

- Step 5: Identify the neutral axis $Z_{\text {NA_cur }}$ at each incremental step.

- Step 6: Identify the corresponding moment through calculation.

- Step 7: Compare the moment in the current incremental step with that in the previous one. The process is terminated and the peak value is defined if the slope in the $M-\chi$ relationship is less than a negative fixed value. Otherwise, increase the curvature by the amount of $\Delta \chi$ and go to step 4 .

Following the aforementioned process, the UBM, $M_{u}$, is identified as the peak point of the $M-\chi$ curve, which results from the bending moment components of all incremental steps expressed by

Table 5 UBM and cross-section properties in case of the corroded bottom panel

\begin{tabular}{|c|c|c|c|c|c|c|c|c|c|c|c|}
\hline Cases & Zones & Year & $A\left(A_{0}\right)$ & $I\left(I_{0}\right)$ & $S M\left(S M_{0}\right)$ & $S M\left(S M_{0}\right)$ & $N A\left(N A_{0}\right)$ & $M_{\mathrm{uh}}\left(M_{\mathrm{uh} 0}\right)$ & $g_{\text {uh }}\left(g_{\text {uh } 0}\right)$ & $M_{\mathrm{us}}\left(M_{\mathrm{us} 0}\right)$ & $g_{\text {us }}\left(g_{\text {us } 0}\right)$ \\
\hline PA1 & Entire & $0-7.5$ & 1.000 & 1.000 & 1.000 & 1.000 & 1.000 & 1.000 & 1.000 & 1.000 & 1.000 \\
\hline PL2 & Plates & 10 & 0.999 & 0.999 & 1.000 & 0.997 & 1.001 & 0.999 & 1.002 & 0.995 & 0.989 \\
\hline PL3 & & 15 & 0.997 & 0.996 & 0.999 & 0.992 & 1.003 & 0.998 & 0.987 & 0.986 & 0.995 \\
\hline PL4 & & 20 & 0.995 & 0.993 & 0.998 & 0.987 & 1.005 & 0.997 & 0.991 & 0.976 & 1.001 \\
\hline PL5 & & 25 & 0.992 & 0.990 & 0.997 & 0.982 & 1.008 & 0.996 & 0.995 & 0.967 & 1.007 \\
\hline PL6 & & CSR net & 0.979 & 0.971 & 0.991 & 0.951 & 1.021 & 0.988 & 1.020 & 0.910 & 1.017 \\
\hline ST2 & Stiffeners & 10 & 0.999 & 0.999 & 1.000 & 0.998 & 1.001 & 1.000 & 1.001 & 0.999 & 1.001 \\
\hline ST3 & & 15 & 0.998 & 0.997 & 0.999 & 0.995 & 1.002 & 0.999 & 1.003 & 0.996 & 1.003 \\
\hline ST4 & & 20 & 0.997 & 0.996 & 0.999 & 0.992 & 1.003 & 0.998 & 0.987 & 0.993 & 1.005 \\
\hline ST5 & & 25 & 0.995 & 0.994 & 0.998 & 0.989 & 1.005 & 0.998 & 0.989 & 0.990 & 1.007 \\
\hline ST6 & & CSR net & 0.983 & 0.978 & 0.993 & 0.961 & 1.017 & 0.991 & 1.010 & 0.970 & 1.011 \\
\hline PA2 & Panel & 10 & 0.998 & 0.998 & 0.999 & 0.996 & 1.002 & 0.999 & 1.003 & 0.994 & 0.990 \\
\hline PA3 & & 15 & 0.995 & 0.993 & 0.998 & 0.988 & 1.005 & 0.997 & 0.990 & 0.982 & 0.998 \\
\hline PA4 & & 20 & 0.991 & 0.988 & 0.996 & 0.980 & 1.009 & 0.995 & 0.996 & 0.970 & 1.007 \\
\hline PA5 & & 25 & 0.988 & 0.983 & 0.995 & 0.971 & 1.012 & 0.993 & 1.003 & 0.957 & 1.015 \\
\hline PA6 & & CSR net & 0.962 & 0.948 & 0.984 & 0.912 & 1.039 & 0.977 & 1.053 & 0.880 & 1.042 \\
\hline
\end{tabular}

0 , original; $h$, hogging; $s$, sagging 
$M_{u}=\sum \sigma_{u i} A_{i-n 50}\left(Z_{i}-Z_{\text {NA_cur }}\right)$

where: $\sigma_{u i}$ is the stress of element, $A_{i}$ is the net cross-sectional area of the element, $Z_{i}$ is the vertical distance from the baseline to the horizontal neutral axis of the element, and $Z_{\mathrm{NA} \text { cur }}$ is the current position of the neutral axis from the baseline.

\subsection{Ultimate Stress of the Structural Elements}

By the IACS-CSR guidelines, the transverse cross-section is divided into three types of elements namely hard corner element, stiffened plate element, and stiffener element, as shown in Figure 2. In identifying the weakest inter-frame failure mode, all relevant failure modes for individual structural elements are considered. Table 1 presents the corresponding failure modes and stress-strain relationships (IACS 2017).

\subsection{Corrosion Model}

To take into account the corrosion wastage, two corrosion models are employed such as the CSR corrosion addition model and probabilistic corrosion rate estimation model. The former is given by IACS-CSR, and the latter is suggested by Paik et al.

The corrosion addition is required in IACS-CSR guidelines for the ship design to achieve a 25 -year design life. The corrosion addition margin is different for every thickness member such as the attached plating, flange thickness, and web thickness and different structural location member groups such as the deck, side, and bottom. The net scantlings in the CSR design are taken into account as the reference scantlings in the current study. Figure 3 presents the corrosion addition margins of different location member groups of a bulk carrier (IACS 2017).

Paik et al. proposed a probabilistic corrosion model which was developed based on the measured data obtained from corroded oil tankers. Hence, the authors consider this model as the most suitable among other options in assessing the effect of corrosion on the responses of oil tanker structures. As indicated in Figure 4, the corrosion model is divided into two phases, one related to the coating life and the other concerned with the progress of corrosion, but without transition duration. The corrosion rate $r(t)$ and corrosion wear $d(t)$ are defined respectively as (Paik et al. 2003a):

$r(t)=C_{1}$

$d(t)=C_{1}\left(t-T_{0}\right)^{C_{2}}$

where $C_{1}$ is the annualized corrosion rate which follows the Weibull distribution, $C_{2}$ is the coefficient and assumed to be $1.0, t$ is the age of the ship, and $T_{0}$ is the coating life.

Figure 5 shows the annual corrosion rate of individual structural member groups of a bulk carrier. The corrosion rate is the average level of corrosion wastage with the assumed coating lifetime of 7.5 years. Meanwhile, the identifications of member location groups are declared in Table 2.

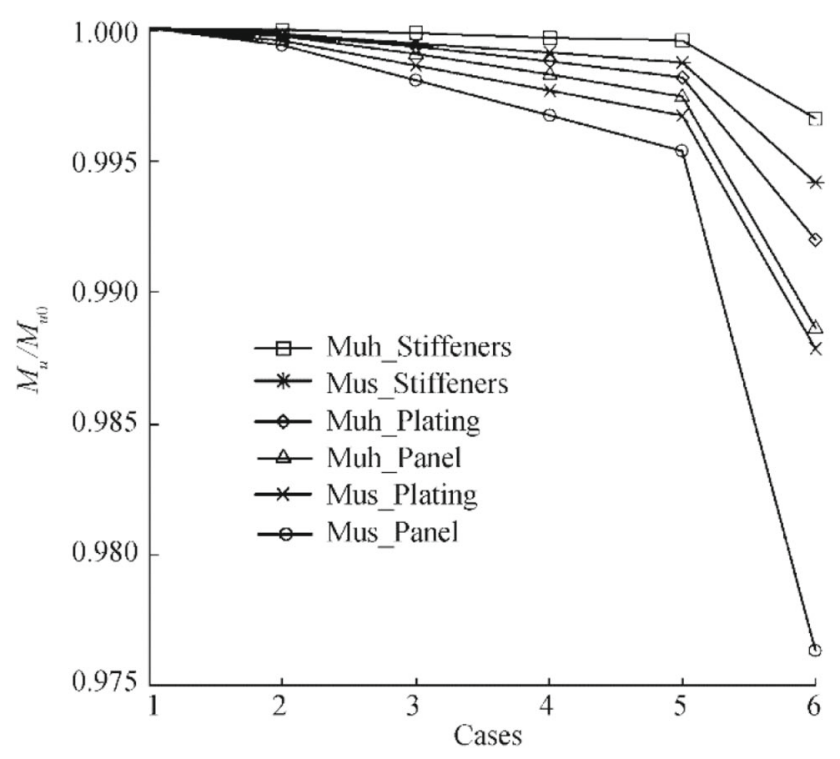

(a) Variations of UBM under the corroded bottom panel

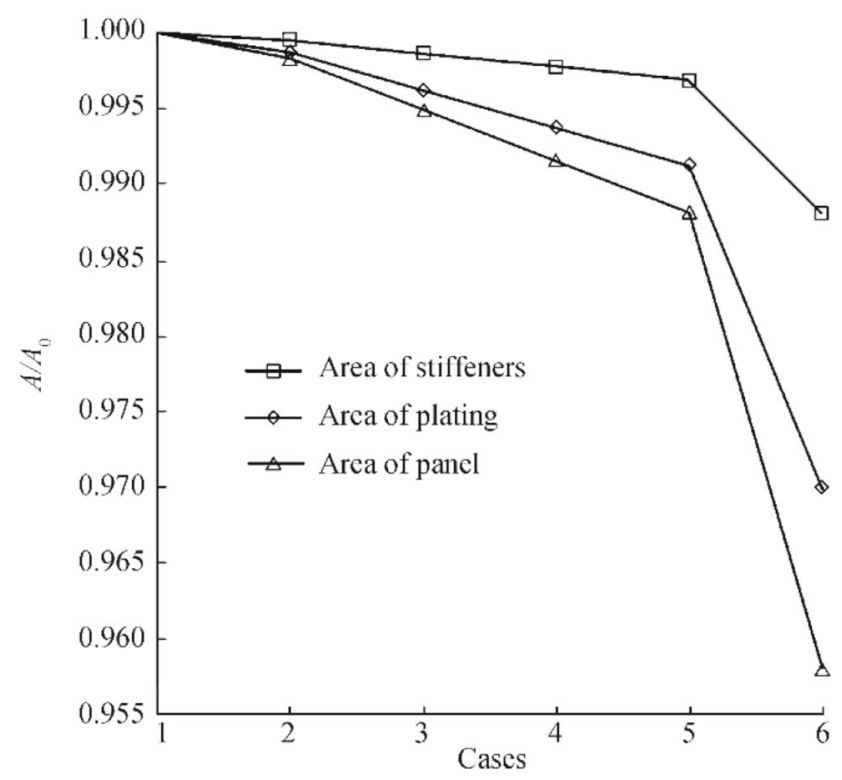

b) Variations of CSA under the corroded bottom panel

Figure 9 Case of corrosion appearance in the bottom panel. a Variations of UBM under the corroded bottom panel. b Variations of CSA under the corroded bottom panel 
Table 6 UBM and cross-section properties in case of the corroded side panel

\begin{tabular}{|c|c|c|c|c|c|c|c|c|c|c|c|}
\hline Cases & Zones & Year & $A\left(A_{0}\right)$ & $I\left(I_{0}\right)$ & $S M\left(S M_{0}\right)$ & $S M\left(S M_{0}\right)$ & $N A\left(N A_{0}\right)$ & $M_{\mathrm{uh}}\left(M_{\mathrm{uh} 0}\right)$ & $g_{\text {uh }}\left(g_{\text {uh0 }}\right)$ & $M_{\mathrm{us}}\left(M_{\mathrm{us} 0}\right)$ & $g_{\text {us }}\left(g_{\text {us } 0}\right)$ \\
\hline PA1 & Entire & $0-7.5$ & 1.000 & 1.000 & 1.000 & 1.000 & 1.000 & 1.000 & 1.000 & 1.000 & 1.000 \\
\hline PL2 & Plates & 10 & 0.998 & 0.999 & 0.999 & 1.000 & 0.999 & 0.998 & 0.998 & 0.998 & 0.999 \\
\hline PL3 & & 15 & 0.995 & 0.997 & 0.996 & 0.999 & 0.998 & 0.993 & 1.014 & 0.995 & 0.996 \\
\hline PL4 & & 20 & 0.992 & 0.995 & 0.994 & 0.999 & 0.997 & 0.990 & 0.979 & 0.991 & 0.993 \\
\hline PL5 & & 25 & 0.989 & 0.994 & 0.991 & 0.998 & 0.995 & 0.985 & 0.976 & 0.988 & 0.990 \\
\hline PL6 & & CSR net & 0.964 & 0.977 & 0.967 & 0.996 & 0.981 & 0.944 & 0.979 & 0.954 & 0.975 \\
\hline ST2 & Stiffeners & 10 & 1.000 & 1.000 & 0.999 & 1.000 & 1.000 & 0.999 & 0.999 & 0.999 & 1.000 \\
\hline ST3 & & 15 & 0.999 & 0.999 & 0.998 & 0.999 & 0.999 & 0.996 & 0.997 & 0.998 & 0.999 \\
\hline ST4 & & 20 & 0.998 & 0.998 & 0.997 & 0.999 & 0.999 & 0.994 & 1.016 & 0.996 & 0.998 \\
\hline ST5 & & 25 & 0.998 & 0.997 & 0.996 & 0.999 & 0.998 & 0.992 & 1.015 & 0.995 & 0.997 \\
\hline ST6 & & CSR net & 0.992 & 0.991 & 0.988 & 0.996 & 0.995 & 0.977 & 0.974 & 0.984 & 0.991 \\
\hline PA2 & Panel & 10 & 0.998 & 0.999 & 0.998 & 1.000 & 0.999 & 0.996 & 0.997 & 0.998 & 0.998 \\
\hline PA3 & & 15 & 0.994 & 0.996 & 0.994 & 0.999 & 0.997 & 0.991 & 0.980 & 0.993 & 0.994 \\
\hline PA4 & & 20 & 0.990 & 0.993 & 0.990 & 0.998 & 0.995 & 0.984 & 0.976 & 0.988 & 0.991 \\
\hline PA5 & & 25 & 0.987 & 0.990 & 0.987 & 0.997 & 0.993 & 0.977 & 0.971 & 0.982 & 0.987 \\
\hline PA6 & & CSR net & 0.957 & 0.968 & 0.954 & 0.992 & 0.975 & 0.922 & 0.966 & 0.938 & 0.980 \\
\hline
\end{tabular}

\section{Demonstrative Example}

A bulk carrier is applied to assess the effect of local corrosion wastage on the vertical bending moment capacity and other properties of the cross-section. The main principles of the selected ship are presented in Table 3 .

To determine the influence of the local corrosion wastage, three assumptions of member structural groups are defined. The first group is the deck panel which

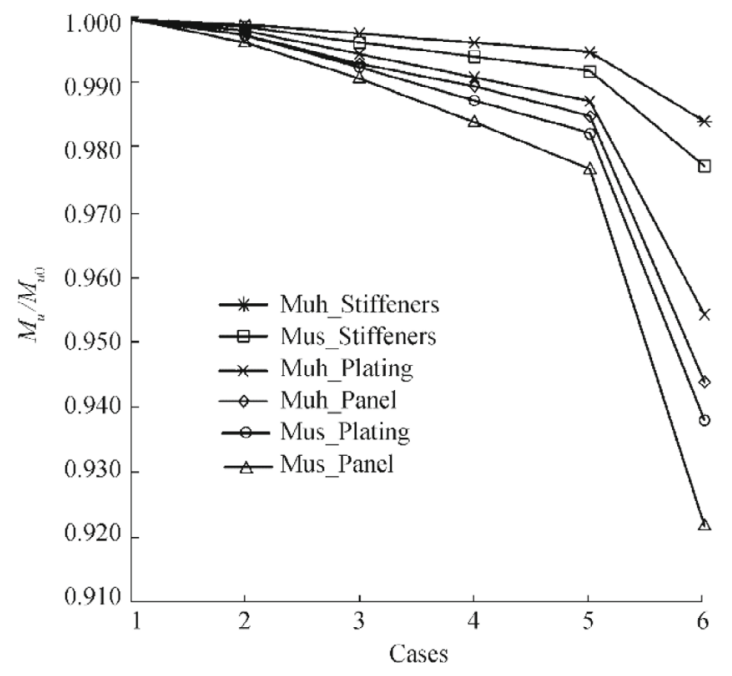

(a) Variations of UBM under the corroded side panel includes deck plating, deck longitudinal stiffeners, and deck girders. The second group contains the longitudinal members of the side shell including side plating, side longitudinal stiffeners, and side girders. The last one is the bottom panel including bottom plating, bottom longitudinal stiffeners, and bottom girders. These mentioned categories are shown in Figure 6.

The corrosion wastage is applied with three assumptions of corrosion appearance to desire a full assessment of the effect

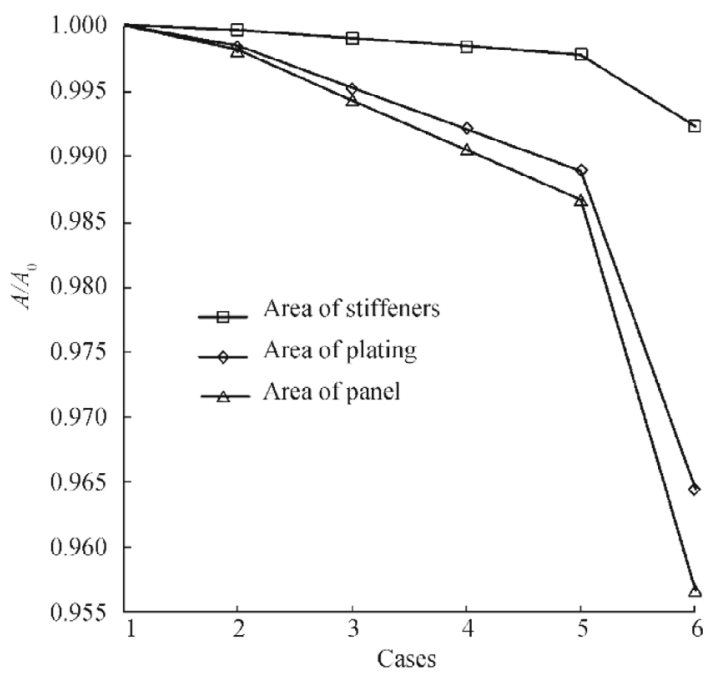

(b) Variations of CSA under the corroded side panel

Figure 10 Case of corrosion appearance in side panel. a Variations of UBM under the corroded side panel. b Variations of CSA under the corroded side panel 
Table 7 UBM and cross-section properties in case of the corroded deck panel

\begin{tabular}{llllllllllll}
\hline Cases & Zones & Year & $A\left(A_{0}\right)$ & $I\left(I_{0}\right)$ & $S M\left(S M_{0}\right)$ & $S M\left(S M_{0}\right)$ & $N A\left(N A_{0}\right)$ & $M_{\text {uh }}\left(M_{\text {uh0 }}\right)$ & $g_{\text {uh }}\left(g_{\text {uh0 }}\right)$ & $M_{\text {us }}\left(M_{\text {us } 0}\right)$ & $g_{\text {us }}\left(g_{\text {us } 0}\right)$ \\
\hline PA1 & Entire & $0-7.5$ & 1.000 & 1.000 & 1.000 & 1.000 & 1.000 & 1.000 & 1.000 & 1.000 \\
PL2 & Plates & 10 & 0.999 & 0.997 & 0.996 & 0.999 & 0.998 & 0.996 & 0.998 & 0.995 & 0.997 \\
PL3 & & 15 & 0.997 & 0.991 & 0.988 & 0.997 & 0.994 & 0.989 & 1.014 & 0.984 & 0.990 \\
PL4 & & 20 & 0.994 & 0.985 & 0.979 & 0.995 & 0.990 & 0.984 & 0.980 & 0.973 & 0.983 \\
PL5 & & 25 & 0.992 & 0.979 & 0.971 & 0.993 & 0.986 & 0.977 & 0.977 & 0.963 \\
PL6 & & CSR net & 0.985 & 0.959 & 0.944 & 0.986 & 0.973 & 0.952 & 0.966 & 0.928 \\
ST2 & Stiffeners & 10 & 1.000 & 0.999 & 0.999 & 1.000 & 0.999 & 0.997 & 0.998 & 0.999 \\
ST3 & & 15 & 0.999 & 0.997 & 0.996 & 0.999 & 0.998 & 0.992 & 1.014 & 0.995 \\
ST4 & & 20 & 0.998 & 0.995 & 0.993 & 0.998 & 0.997 & 0.988 & 0.980 & 0.992 \\
ST5 & & 25 & 0.997 & 0.993 & 0.990 & 0.998 & 0.995 & 0.983 & 0.977 & 0.988 \\
ST6 & & CSR net & 0.992 & 0.980 & 0.972 & 0.993 & 0.986 & 0.930 & 0.963 & 0.967 & 1.010 \\
PA2 & Panel & 10 & 0.998 & 0.996 & 0.994 & 0.999 & 0.997 & 0.994 & 0.996 & 0.993 & 0.992 \\
PA3 & & 15 & 0.995 & 0.988 & 0.983 & 0.996 & 0.992 & 0.984 & 0.979 & 0.979 & 0.996 \\
PA4 & & 20 & 0.992 & 0.980 & 0.972 & 0.993 & 0.986 & 0.972 & 0.973 & 0.965 & 0.990 \\
PA5 & & 25 & 0.989 & 0.972 & 0.961 & 0.990 & 0.981 & 0.960 & 0.968 & 0.951 & 0.968 \\
PA6 & CSR net & 0.977 & 0.938 & 0.917 & 0.979 & 0.959 & 0.895 & 0.949 & 0.894 & 0.948 \\
\hline
\end{tabular}

of local corrosion on the behaviors of structures. Firstly, the corrosion is assumed that only the attached plating is corrosive. Then, all the thickness members of the longitudinal stiffeners are reduced due to corrosion wastage. Finally, the entire panel is assumed as a corroded panel.

Figures 7 and 8 combined with Table 4 present the detailed information of the thickness degradation of the attached plat$\operatorname{ing}\left(t_{\mathrm{p}}\right)$, thickness of web $\left(t_{\mathrm{w}}\right)$, and thickness of flange $\left(t_{\mathrm{f}}\right)$. The " $g r$ " is denoted for gross, and "net" is defined as the net scantling of the thickness.

\section{Results and Discussions}

\subsection{Case of Corrosion Appearance in the Bottom Panel}

Table 5 and Figure 9a, b present the calculation results of UBMs and several cross-section properties under the corrosion appearance in the bottom panel of the selected bulk carrier. The information is classified into six cases of corrosion wastage and three structural member groups such as attached plating, stiffeners, and entire panel. The variations of UBM $\left(M_{\mathrm{u}}\right)$ and neutral axis position at the limit state $\left(g_{\mathrm{u}}\right)$ combined with cross-section properties such as total cross-sectional area $(A)$, moment of inertia $(I)$, section modulus at deck and bottom $(S M)$, and neutral axis of cross-section (NA) are illustrated.

The appearance of corrosion at the bottom panel causes the reduction of cross-sectional area (CSA) of both attached plating and stiffeners by $0.8 \%$ (case PL5) for the former and $0.5 \%$ (case ST5) for the later. The effect of corroded plating is much more significant than that of corroded stiffeners on the UBM reduction. For instance, the ultimate sagging bending moment (USBM) reductions are 3.3\% for the case of PL5 and 1.0\% for the case of ST5. When the whole bottom panel is corroded, the USBM reduction is considerable ( $4.3 \%$ for case PA5) while the ultimate hogging bending moment (UHBM) reduction is slight (about $0.7 \%$ for case PA5). This degradation of UBM meets the biggest value in the case of PA6 as nearly $12 \%$.

\subsection{Case of Corrosion Appearance in the Side Panel}

Table 6 and Figure 10a, b show the information related to the effect of corrosion appearance in the side panel on the UBMs and other properties. It can be seen clearly from the table that the CSA reduction of attached plating, stiffeners, and entire side panel are the similar trends in comparison with the case of the corroded bottom. The corrosion appeared in the deck panel affects clearly on the USBM while the side panel under corrosion influences apparently on the UHBM. Specifically, the corrosion diminishes the UHBM by $2.3 \%$ for case PA5 and $7.8 \%$ for case PA6; meanwhile, these values of USMBs reduction are $1.8 \%$ and $6.2 \%$, respectively.

\subsection{Case of Corrosion Appearance in the Deck Panel}

Table 7 and Figure 11a, b give the information of UBMs, neutral axis position at the limit state, and other properties of the cross-section. The CSA reduction of the panel due to corrosion is small. It is about $1.1 \%$ for case PA5, but the UBM reduction is the biggest in comparison with other locations of corrosion 


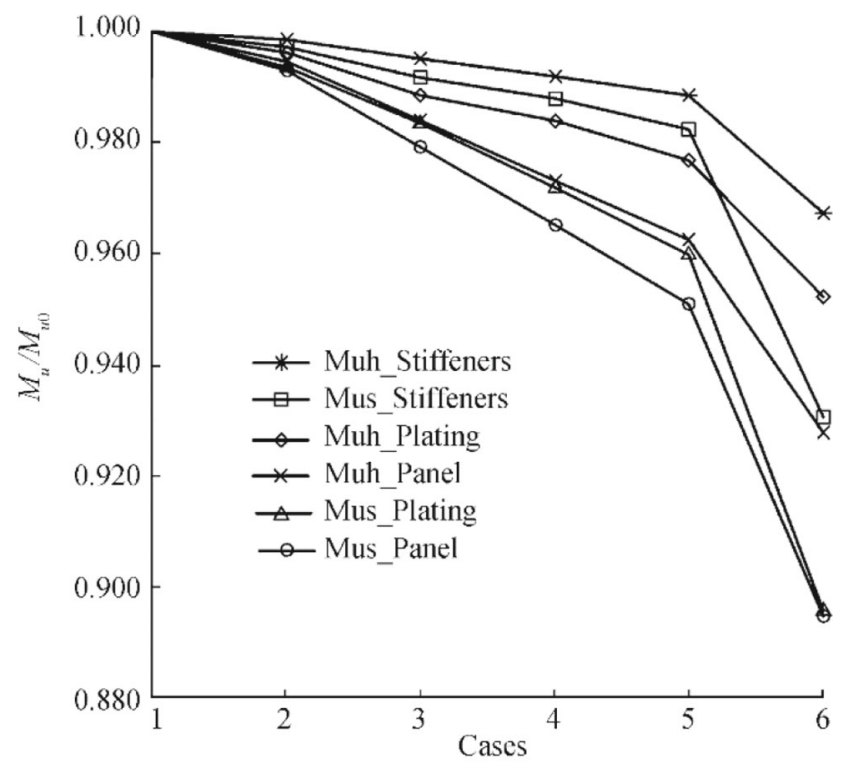

(a) Variations of UBM under corroded deck panel

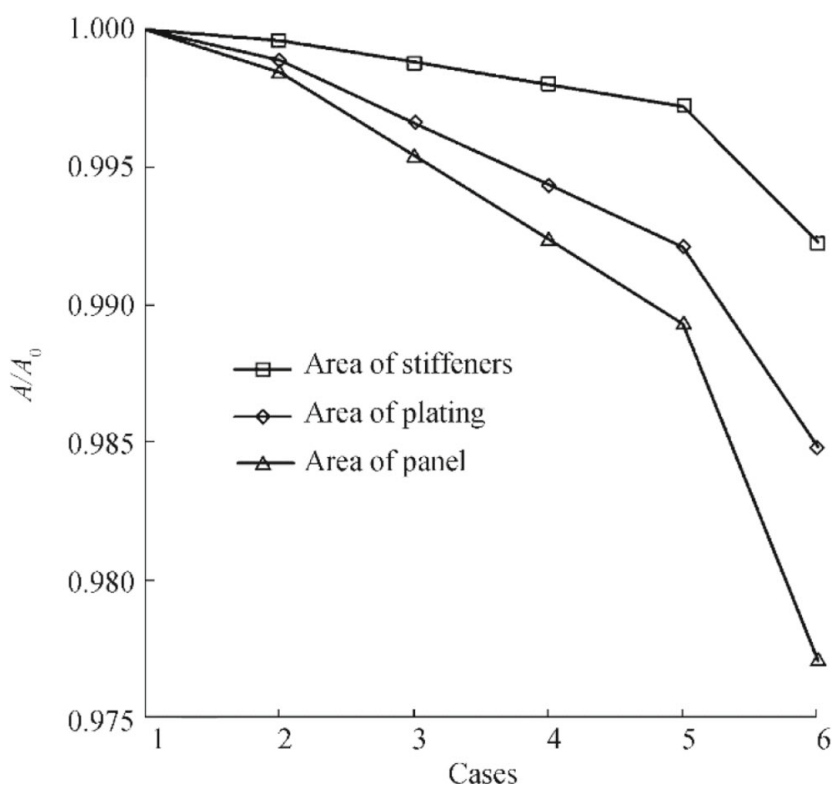

(b) Variations of CSA under corroded deck panel

Figure 11 Case of corrosion appearance in deck panel. a Variations of UBM under corroded deck panel. b Variations of CSA under corroded deck panel

appearance. To be more specific, the UHBM and USBM are reduced by $4.0 \%$ and $4.9 \%$ for case PA5, respectively.

\subsection{Comparison of UBM and CSA of Panel}

The UBMs for hogging and sagging conditions are summarized and shown in Figure 12a. The UBM is obtained for different cases of corrosion appearance locations such as deck, side, and bottom panel. Meanwhile, the variations of CSA of

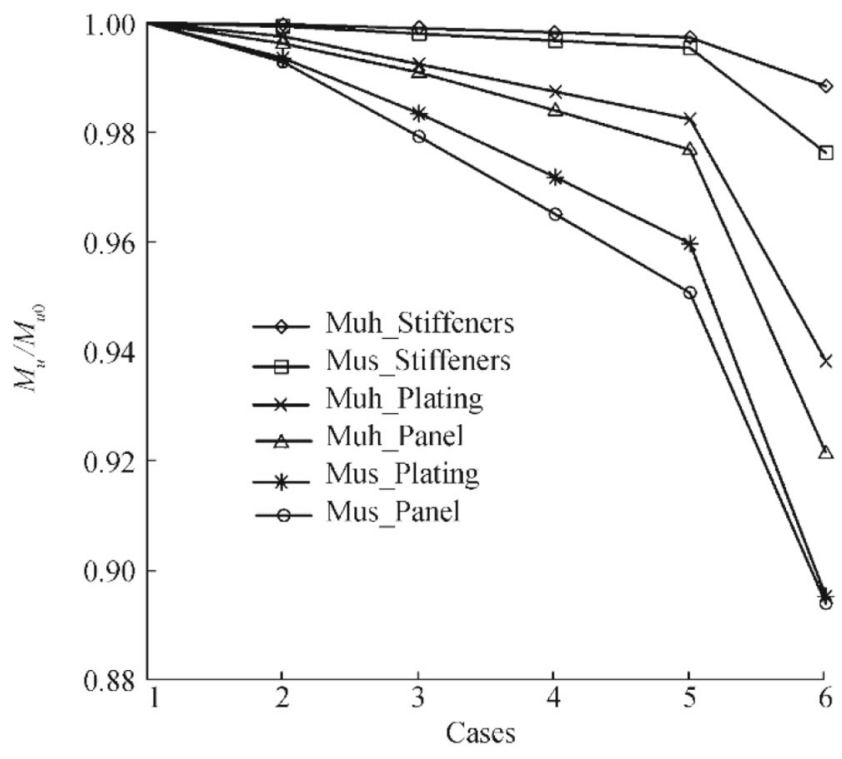

(a) Comparison of the USBM and UHBM

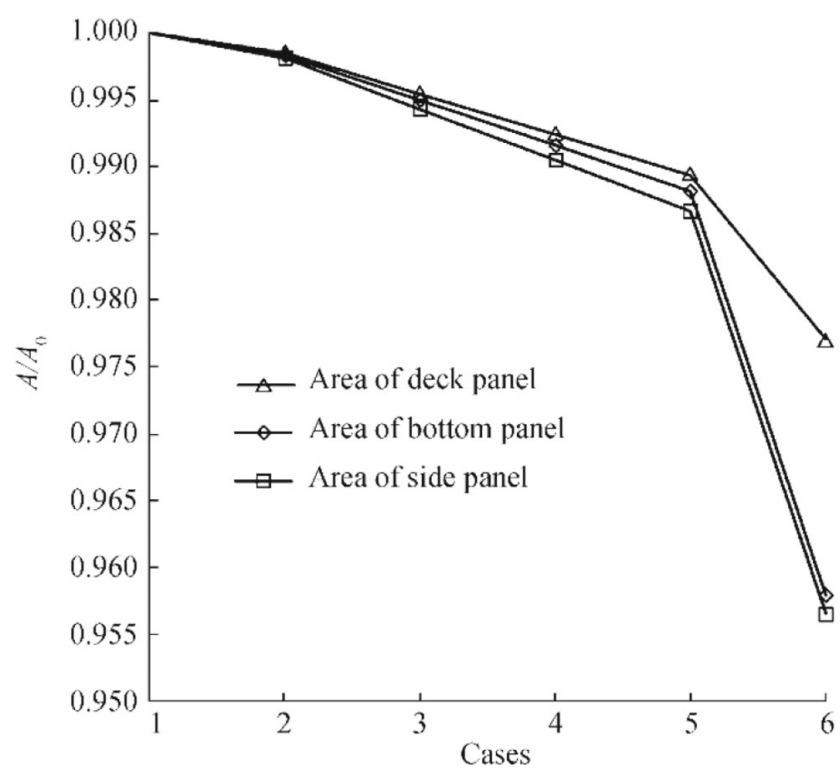

(b) Comparison of the CSA

Figure 12 Ultimate bending moment and cross-sectional area comparisons. a Comparison of the USBM and UHBM. b Comparison of the CSA

deck, side, and bottom panel under corrosion rate or corrosion addition are drawn as in Figure 12b.

It can be seen from Figure $12 \mathrm{~b}$ that the corrosion gives the biggest influence on the CSA reduction of the side panel and this reduction reaches $4.3 \%$ under the corrosion addition specified by the CSR. Although the CSA reduction of deck panel under corrosion is small, its effect on the UBMs and other cross-section properties is the most serious, especially USBM with the reductions are $4.9 \%$ (case PA5) and $10.6 \%$ (case PA6). 


\section{Concluding Remarks}

Several concluding remarks can be drawn as the following list:

(1) The analyses of the ultimate vertical bending moment and cross-section properties of a bulk carrier are performed and compared using the corrosion rate estimation model and CSR corrosion addition.

(2) The total CSA of all longitudinal stiffeners in a panel is smaller than that of the attached plating of the same panel. The longer is the service year, the more obvious discrepancy is between these areas. The diminution of CSA of the deck panel is the smallest, while that of the side panel is the biggest.

(3) The effect of corroded stiffeners on the UBM is smaller than the effect of corroded plating on the UBM. This is true for all of the defined panels such as deck, side, and bottom.

(4) Under the thickness degradation due to corrosion wastage at the side panel, the CSA reduction is biggest, while UBM reduction is smallest in comparison with cases of the corroded deck and corroded bottom. This damaged structure also brings the diminution of UHBM which is bigger than USBM reduction.

(5) On the contrary, UHBM degradation is smaller than USBM oneforboth cases of the corrodeddeck and bottompanels. The appearanceofcorrosionatthedeckpanelisconsidered tobethe mosthazardous on the residual strength of the selected ship.

Open Access This article is licensed under a Creative Commons Attribution 4.0 International License, which permits use, sharing, adaptation, distribution and reproduction in any medium or format, as long as you give appropriate credit to the original author(s) and the source, provide a link to the Creative Commons licence, and indicate if changes were made. The images or other third party material in this article are included in the article's Creative Commons licence, unless indicated otherwise in a credit line to the material. If material is not included in the article's Creative Commons licence and your intended use is not permitted by statutory regulation or exceeds the permitted use, you will need to obtain permission directly from the copyright holder. To view a copy of this licence, visit http://creativecommons.org/licenses/by/4.0/.

\section{References}

Akpan UO, Koko TS, Ayyub B, Dunbar TE (2002) Risk assessment of aging ship hull structures in the presence of corrosion and fatigue. Mar Struct 15(3):211-231

Dunbar TE, Pegg N, Taheri F, Jiang L (2004) A computational investigation of the effects of localized corrosion on plates and stiffened panels. Mar Struct 17(5):385-402

Gao DW, Shi GJ, Wang DY (2012) Residual ultimate strength of hull structures with crack and corrosion damage. Eng Fail Anal 25:316-328

Garbatov Y, Guedes Soares C (2008) Corrosion wastage modeling of deteriorated bulk carrier decks. Int Shipbuild Prog 55(1-2):109-125
Garbatov Y, Guedes Soares C, Wang G (2007) Non-linear time dependent corrosion wastage of deck plates of ballast and cargo tanks of tankers. J Offshore Mech Arct Eng 129(1):48-55

Gaspar B, Teixeira AP, Guedes Soares C, Wang G (2011) Assessment of IACS-CSR implicit safety levels for buckling strength of stiffened panels for double hull tankers. Mar Struct 24(4):478-502

Guedes Soares C, Garbatov Y (1997) Reliability assessment of maintained ship hulls with correlated corroded elements. Mar Struct 10(8):629-653

Guedes Soares C, Garbatov Y (1999) Reliability of maintained ship hulls subjected to corrosion and fatigue under combined loading. J Constr Steel Res 52(1):93-115

Guedes Soares C, Parunov J (2008) Structural reliability of a Suezmax oil tanker designed according to new common structural rules. J Offshore Mech Arct Eng 130(2)

Guedes Soares C, Garbatov Y, Zayeda A, Wang G (2009) Influence of environmental factors on corrosion of ship structures in marine atmosphere. Corros Sci 51(9):2014-2026

Huang Y, Zhang Y, Liu G, Zhang Q (2010) Ultimate strength assessment of hull structural plate with pitting corrosion damnification under biaxial compression. Ocean Eng 37(17-18):1503-1512

IACS (2017) Common structural rules for bulk carriers and oil tankers. International Association of Classification Societies. London, United Kingdom, Jan. $1^{\text {st }}$

Ikeda A, Yao T, Kitamura O, Yamamoto N, Yoneda M, Ohtsubo H (2001) Assessment of ultimate longitudinal strength of aged tankers. Proceedings of the 18th International Symposium on Practical Design of Ships and Other Floating Structures, 2, 997-1003

Jiang XL, Guedes Soares C (2013) Ultimate compressive capacity of rectangular plates with partial depth pits. J Offshore Mech Arct Eng 135(2)

Jing ZG, Xing HS, Guedes Soares C (2017) Experimental analysis of residual ultimate strength of stiffened panels with pitting corrosion under compression. Eng Struct 152(1):70-86

Kaita T, Appuhamy JMRS, Itogawa K, Ohga M, Fujii K (2011) Experimental study on remaining strength estimation of corroded wide steel plates under tensile force. Procedia Eng 14:2707-2713

Kim DK, Park DK, Kim HB, Seo JK, Kim BJ, Paik JK, Kim MS (2012a) The necessity of applying the common corrosion addition rule to container ships in terms of ultimate longitudinal strength. Ocean Eng 49:43-55

Kim DK, Park DK, Park DH, Kim HB, Kim BJ, Seo JK, Paik JK (2012b) Effect of corrosion on the ultimate strength of double hull oil tankers - part II: hull girders. Struct Eng Mech 42(4):531-549

Kim DK, Kim HB, Zhang XM, Li CG, Paik JK (2014a) Ultimate strength performance of tankers associated with industry corrosion addition practices. Int J Nav Architect Ocean Eng 6(3):507-528

Kim DK, Liew MS, Youssef SAM, Mohd MH, Kim HB, Paik JK (2014b) Time-dependent ultimate strength performance of corroded FPSOs. Arab J Sci Eng 39(11):7673-7690

Ok D, Pu YC, Incecik A (2007) Computation of ultimate strength of locally corroded unstiffened plates under uniaxial compression. Mar Struct 20(1-2):100-114

Paik JK (2005) Ultimate strength of dented steel plates under edge shear loads. Thin-Walled Struct 43(9):1475-1492

Paik JK, Kim SK, Lee SK (1998) Probabilistic corrosion rate estimation model for longitudinal strength members of bulk carriers. Ocean Eng 25(10):837-860

Paik JK, Hughes OF, Mansour AE (2001) Advanced closed-form ultimate strength formulation for ships. J Ship Res 45(2):111-132

Paik JK, Lee JM, Hwang JS, Park YI (2003a) A time-dependent corrosion wastage model for the structures of single- and double-hull tankers and FSOs and FPSOs. Mar Technol 40(3):201-217

Paik JK, Lee JM, Ko MJ (2003b) Ultimate compressive strength of plate elements with pit corrosion wastage. Proc Inst Mech Eng M J Eng Marit Environ 217(4):185-200 
Paik JK, Lee JM, Park YI, Hwang JS, Kim CW (2003c) Time-variant ultimate longitudinal strength of corroded bulk carriers. Mar Struct 16(8):567-600

Paik JK, Wang G, Thaamballi AK, Lee JM, Park YI (2003d) Time dependent risk assessment of aging ships accounting for general pit corrosion, fatigue cracking, and local dent damage. For presentation at the 2003 SNAME Annual Meeting in San Francisco, 1-37

Parunov J, Guedes Soares C (2008) Effects of common structural rules on hull-girder reliability of an Aframax oil tanker. Reliab Eng Syst Saf 93(9):1317-1327

Rahbar-Ranji A (2015) Elastic buckling analysis of corroded stiffened plates with irregular surfaces. Sadhana-Acad Proc Eng Sci 40(1): 199-213

Rahbar-Ranji A, Niamir N, Zarookian A (2015) Ultimate strength of stiffened plates with pitting corrosion. Int J Nav Architect Ocean Eng 7:509-525
Saad-Eldeen S, Garbatov Y, Guedes Soares C (2013) Ultimate strength assessment of corroded box girders. Ocean Eng 58:35-47

Vu Van T, Yang P (2017) Effect of corrosion on the ship hull of a double hull very large crude oil carrier. J Mar Sci Appl 16(3):334-343

Wang Y, Wharton JA, Shenoi RA (2015) Ultimate strength assessment of steel stiffened plate structures with grooving corrosion damage. Eng Struct 94:29-42

Zayed A, Garbatov Y, Guedes Soares C (2013) Reliability of ship hulls subjected to corrosion and maintenance. Struct Saf 43:1-11

Zayed A, Garbatov Y, Guedes Soares C (2018) Corrosion degradation of ship hull steel plates accounting for local environmental conditions. Ocean Eng 63:299-306

Zhang D, Huang Y, Zhang Q, Liu G (2016) Ultimate strength of hull structural plate with pitting corrosion damnification under combined loading. Ocean Eng 16:273-285 